\title{
Study of Using Cassava Pulp to Produce Livestock Feed Pellet
}

\author{
Tuan-Anh Bui", Van-Hung Pham*, Huy-Bich Nguyen*, Thanh-Phong Nguyen*, Duc-Khuyen Nguyen*, \\ Van-Cong-Chinh Nguyen ${ }^{*}$ \\ ${ }^{\#}$ School of Mechanical Engineering, Hanoi University of Science and Technology, No.1 Dai Co Viet Rd., Hanoi, Vietnam \\ E-mail: anh.buituan@hust.edu.vn
}

*Nong Lam University Hochiminh city, Linh Trung Ward, Thu Duc District, Hochiminh city, Vietnam

E-mail:nhbich@hcmuaf.edu.vn

\begin{abstract}
In Vietnam, the cassava production capacity is about 10 million tons annually. Indeed, it eliminates approximate 4 million tons of cassava pulp from the cassava starch factories. This amount of cassava is usually dried to feed cattle or fertilizer. However, drying of cassava pulp has its disadvantages such as air pollution, difficult storage and transportation. This study has proposed and successfully tested a line of equipment used to produce pellets from the utilization of fresh cassava pulp bringing from cassava starch processing plants. The processing includes a mixing of fresh cassava pulp with dried cassava starch, pressing and drying of pellets. The experiment results show that when the mixing ratio between cassava starch and cassava residue is $1: 10$ - 1:5, the cassava pulp pellets after drying achieved the required technical specifications. Hence, it has high volume density, the dried specific weight of the pellets is about $700 \mathrm{~kg} / \mathrm{m3}$, the breaking strength of the pellets is greater than $2 \mathrm{kG}$, the tanning time of the pellets is greater than 116 minutes in water, the moisture content of the pellets is remained in $13 \%$ after drying in 5-5.5 hours.
\end{abstract}

Keywords - Cassava pulp; cassava starch; pressing screw; mixing machine; livestock feed.

\section{INTRODUCTION}

Cassava (Manihot esculenta Crantz), which originated in South America, is the third most important source of calories in the tropics [1]. In terms of global annual production, it is the sixth most important food crop after sugar cane, maize, rice, wheat and potato [2]. Nowadays, cassava is cultivated as an annual crop in subtropical and tropical regions of the world. According to FAO statistics [3], Worldwide production of cassava is around 268.28 million tons in year 2014. Nigeria is the largest producer of cassava in the World, producing over 54 million tonnes, followed by Thailand, Indonesia, Brazil and Ghana [3]. The root of cassava is processed into multitude of products, such as food, flour, animal feed, alcohol etc [4].

In Vietnam, cassava is a traditional crop, and is now grown throughout the country. Nowadays, it is considered one of the most important food crop, after rice and corn. Vietnam is among the 10 largest cassava producers in the world [3]. In 2016, the cassava area in Vietnam reached 569,900 ha, with a production of 10.93 million tonnes [5]. In Vietnam, there are over 100 large-scale cassava processing factories with total processing capacity of 38 million tons cassava roots per year. In addition, there are over 4000 small-scale cassava processing units in all over the country
[6]. The by-product remaining after starch extraction is cassava pulp, represents from $10 \%$ to $15 \%$ of the fresh roots weight [7]. This is equivalent to about 3,8 to 5,4 million tons of pulp discharge each year.

In the cassava starch processing, pulp waste is the main problem. Due to the high starch and moisture content (75$85 \%$ ), cassava pulp spoils rapidly causing environmental problems with disposal. It contaminates the air, water and wells of people living near the factories. Cassava pulp contains a large amount of starch, which is up to $50 \%$ on dry weight basis [8]. The pulp also has a high fibre content (about 10\%-20\%, dry weight basis) and contains minerals such as $\mathrm{Cu}, \mathrm{Zn}, \mathrm{Mn}, \mathrm{Fe}$ and $\mathrm{Mg}$ [8]. Starch and cellulose contained in cassava pulp are potential sources of carbohydrates which could be converted into different kinds of chemicals or products as well as for energy such as biogas, animal stuff, ethanol, and fertilizer etc [9]. The utilization of cassava pulp would be beneficial since the material is abundantly and continuously available in many cassava processing factories. In addition, it would solve the environmental problem of cassava pulp disposal [10].

In Vietnam, at least 3.8 million tons of cassava pulp is generated annually. The fresh pulp from processing factory is usually sold to pulp collectors that sundry it and sell the dry pulp to animal feed processors [11]. The price of cassava 
pulp is very low and is highly fluctuating. The price of fresh pulp and dried pulp are about 50-200 VND per kilogram and 2.000-3.000 VND per kilogram, respectively [12]. The wet pulp is usually dried by sun or dryer to a moisture content of $10-13 \%$. After drying, cassava pulp is used for production of animal feed [12]. Traditional sun-drying is very slow and inefficient. It typically would take 3 to 5 days to dry one batch depending on the weather condition; a large area is needed for drying the cassava pulp; open sun-drying causes a serious air pollution. In addition, transportation of dried cassava pulp is inconvenience due to its high specific volume and serious air pollution caused by dust generation during loading and unloading the pulp powder.

Recently, several studies have been successful in producing cassava pulp pellet by adding a small amount of dried cassava starch into the wet cassava pulp [13-15]. The pellet production process involved dewatering cassava pulp, pellet extrusion and drying the pellet. Basically, this process solves the problem of cassava pulp processing and utilization such as it is easier for drying process, transportation and it helps solve the air pollution issue. However, the strength of the pellets produced by the process is low. The broken ratio of the dried pellet was estimated about $50 \%$. Therefore, the pellets do not meet the requirements of the feedstuff industry. This study aims to improve the production process of the feedstuff pellets by evaluating the effect of cassava pulpcassava starch mixing ratio on the physical properties of the feedstuff pellets.

\section{MATERIAL AND METHOD}

The process of producing pelleted pellets from cassava pulp is shown in Figure 1. Cassava pulp after processing with very high moisture content, which is about $80-85 \%$, is rinsed with water until it reaches a moisture approximate $67 \%$. Cassava pulp is then added to the mixer proportionate to amount of dried cassava starch. The process of mixing cassava starch into cassava pulp is to increase the bonding and increases the strength. It will result in reducing the breakage rate during drying and transportation. The determination of the composition of cassava residue and starch content and the uniformity of these two components greatly influenced the quality of the feed pellets. After mixing, the mixture is passed through a pelletizer for forming the livestock feed pellets, which means tightening the product, increasing its own density, reducing its moisture absorption and oxidation capacity, and making stable quality of nutrition.

According to the current technology using screw to press the pellets, the cassava pulp is pushed under the effect of the pressed screw, the feed material has been gelatinized under the effect of the resistor located along the pressed screw. After being gelatinized, the material is pushed into the mould. The material exiting the mould is cut by a cutting member. Once the cassava pellets are formed with a high moisture, they are necessary to pass through the drying process to reduce the moisture content. Hence, it will increase the storage time and make easier in transportation of the livestock feeds pellet.

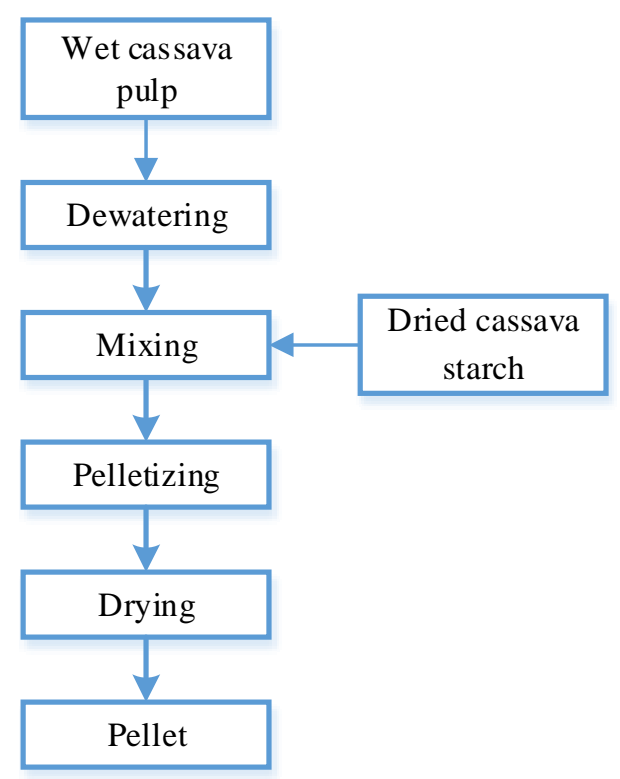

Fig. 1. Flowchart for cassava pulp pellet production

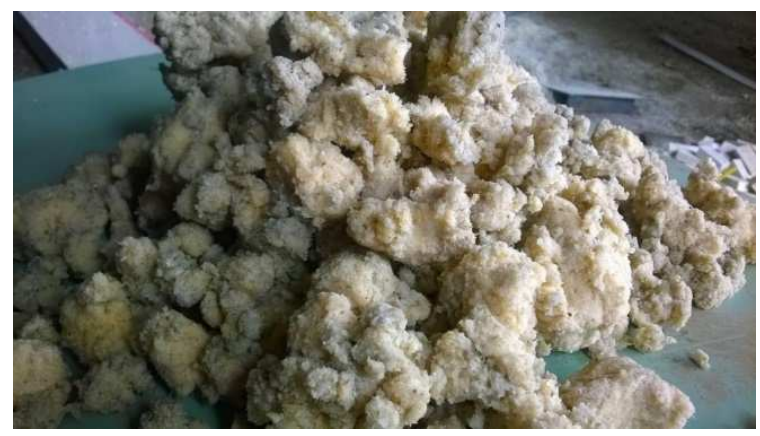

Fig. 2. Cassava pulp used as the experimental material

\section{A. Experimental material}

The cassava pulp used in the experiment was obtained from the wheat flour processing plant of FOCOCEV factory in Binh Phuoc province (shown in Figure 2). Cassava pulp was extracted with tap water VBS-14 to $65 \%$ moisture content. The specific weight of cassava pulp is about 1200 $\mathrm{kg} / \mathrm{m}^{3}$. The coefficient of friction of cassava pulp is 0.6 [13].

\section{B. Study method}

The mixture parameters were measured indirectly through the same production tests. Determination of consistency was done by evaluating the strength and compressibility of pellets after drying. In addition, the uniformity of the viscous mixer was evaluated by adding the pigments during mixing in proportion to that of cassava starch.

Resilience of the pellet is the ability to overcome the impact of an external force or the environment effect of a pellet that retains its original shape and is not destroyed. The pellet strength is determined by immersion method. Stamina is characterized by immersion time that the tablet is not destroyed. Water in the cup takes $2 / 3$ of the cup $(1000 \mathrm{ml})$ for 100 grams in a cup of water. Observe and count the time that starts when the tablet is dropped until it starts disintegrating.

The hardness of the pellets was checked using the K31750000 Pellet Hardness Tester from Amandus Kahl company, Germany. 
The Vietnam standard TCVN 102: 2004 was used to compare and evaluate the strength and hardness of the pellets. Cassava residue is required to be stable when the cassava pulp has reached the minimum dissipation time about 60 minutes in water. The compressive strength of the pellets should be over $2 \mathrm{kG}$ so that the pellets can be stored for a long time and avoid breaking during transportation.

Samples experimented was selected completely randomized. Experimental data were analyzed using the variance analysis to evaluate the deviation of the experimental value, the correlation of the study factors and the suitability of the experimental statistical model.

\section{Experiment devices}

\section{1) Mixing machine}

The characteristics of the input material include the different moisture content, which necessitates large mixing and shifting of the mixing material. Based on the designed capacity, technical requirements and the characteristics of the wet mixer, the mixer is chosen with a continuously horizontal pitch screw as the mixer. Due to the continuous mixing characteristics of the mix, the feed must be consistent and quantitative over time. Therefore, the feeder is designed as two loading screws to feed material continuously, and be able to adjust the capacity by the number of revolutions of the screw. Two feed screws are driven by two separate inverters. The rotational speed of each screw is controlled by an inverter with the frequency from 1 to $50 \mathrm{~Hz}$. Thus, the level of each feed screw is completely adjustable to each level required. It is enabling to continuously feed both the wheat and wheat flour ingredients in a consistent mixing ratio. Depending on the mix ratio chosen and the productivity of the mixer, the amount of flour and wheat residue for each batch is calculated. The machine will be tested to determine a feasible revolution of each feed screw before conducting the official experiments.

Principle of operation: The mixed material is fed into the feeder (1) at the top of feeder door. When operating the machine, the gearbox motor (5) transmits motion to the main shaft (4) via the chain transmission (6). Because the centrifugal blades (3) are attached to the screw pitch, the mixture is not only blended but also transported along the blender shaft. The product is pulled out at the exit door (7) which is at the end of the mixing tank (2). The mixing quality of this mixer depends on the mixing time and it is determined by experiment. Mixing time should be suitable with the time of product transfer in the mixer from the feeder door (1) to the discharge door (7). The mixing time can be changed by changing the revolution of the mixing shaft (4) as well as the angle of the mixing blade (3) on the shaft. The tilted blades installed will increase the mixing effect.

\section{2) Pressing machine}

A plate-roller model of the pressed machine is used to press the tablet during the experiment. The material is fed to the feed hopper (4). The motor (1) drives the gearbox (7) through the coupling to reduces the speed and transfers power from the motor to the mould (9) while also makes the roller turning. As the mould rotates, the material is swirled into the gap between the mould surface and the rollers, gradually pressed down and pushed through the mould hole

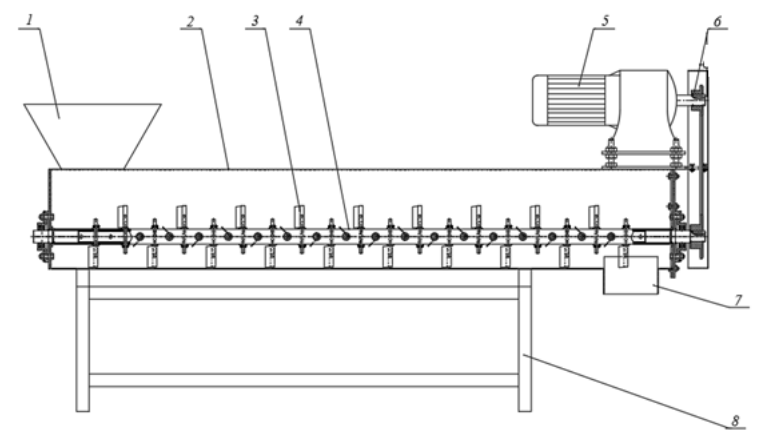

Fig.3. Mixing machine for experiments

1. Material inlet; 2. Mixing chamber; 3. Blades; 4. Mixing shaft; 5. Gearbox motor; 6. The transmission chain; 7. Material outlet; 8. Base frame of machine.

to make the tablet and then they are pulled out through the discharge hopper (6), the pressing force is adjusted through the adjustable screw nut to change the spring force on the roller.

\section{3) Drying machine}

The dryer used in the experiment is a flat bed dryer. The operation principle of the device: axial fan (1) pushes air from the external environment through the resistance box, the air is heated to the given temperature. After that, the hot air flow continues going through the reversing unit inclduding the windscreen wing and the two distributed doors to the drying chamber. If the upper door is closed by the air reversal wing, the drying agent will enter the drying chamber at the bottom distribution door and then pass through the material from the bottom upwards and bring the moisture outward to the upper outlet. In contrast, if the lower door is closed by the air reversal wing, the drying agent enters the drying chamber at the upper distribution door and passes through the material in the upward direction and also brings the moisture outward under the lower outlet. During the drying process, the wind is reversed so that the drying material is uniformly dried. The drying temperature is automatically controlled by the control cabinet.

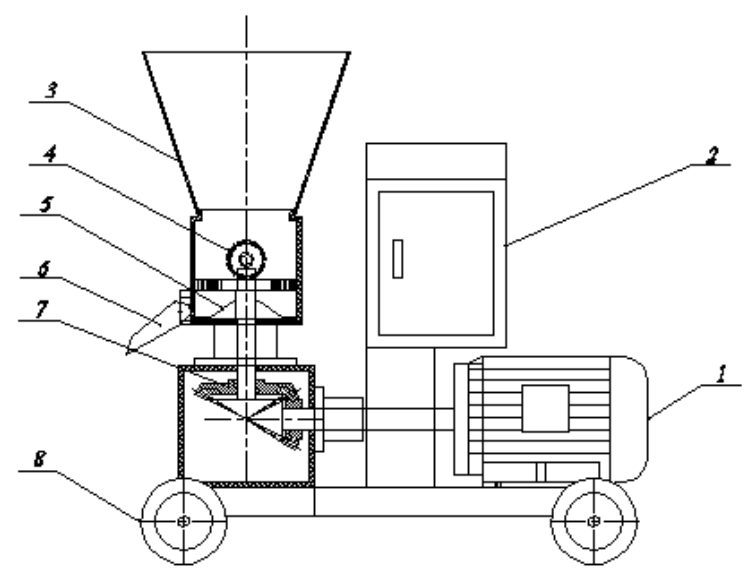

Fig.4. Pelleting machine for experiments

1. Motor; 2. Control box; 3. Feed hopper; 4. Roller; 5. spinning disc; 6 . Retrieval funnel; 7. Gear box; 8. Wheels; 


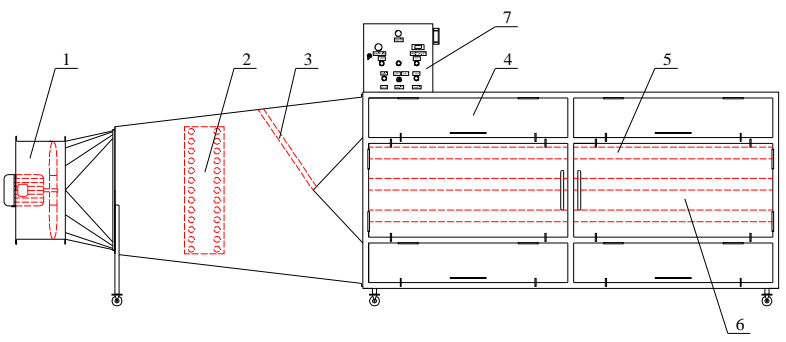

Fig.5. Drying machine for experiments

1. Fans, 2. Resistivity, 3. Wind wing, 4. Drainage door, 5. Drying tray, 6. Drying door, 7. Electric control cabinet.

\section{RESULTS AND DISCUSSION}

\section{A. Determination of the yield of two quantitative load screws}

Trial test of dried powdered cassava transportation screw for the mixer (transportation screw No.1):

The purpose of the test is to determine the actual yield of the dried cassava powder transportation screw in proportion to the screw revolutions. The results are shown in Figure 6.

The test results show that the transportation screw operation is stable, the productivity of the dried cassava powder transportation screw satisfies the productivity of the mixer. The actual capacity of the loading screw varies almost linearly with the screw revolution with a high correlation coefficient, R2 $=0.997$. This illustrates that the loading screw has been designed to be suitable for loading materials such as dried cassava powder. Actual screw yield for the experiments in this study was calculated according to empirical formula as follows:

$$
Q=19.142 \times n-32.34 \quad[\mathrm{~kg} / \mathrm{hr}]
$$

According to experiment results, the experimental model is consistent with significance level $\alpha=0.01$.

Screw test of cassava residue load for mixer (loading screw No.2)

The purpose of the experiment was to determine the actual capacity of the cassava pulp loading screw in proportion to the screw revolutions. The trial experiment results are shown in Figure 7.

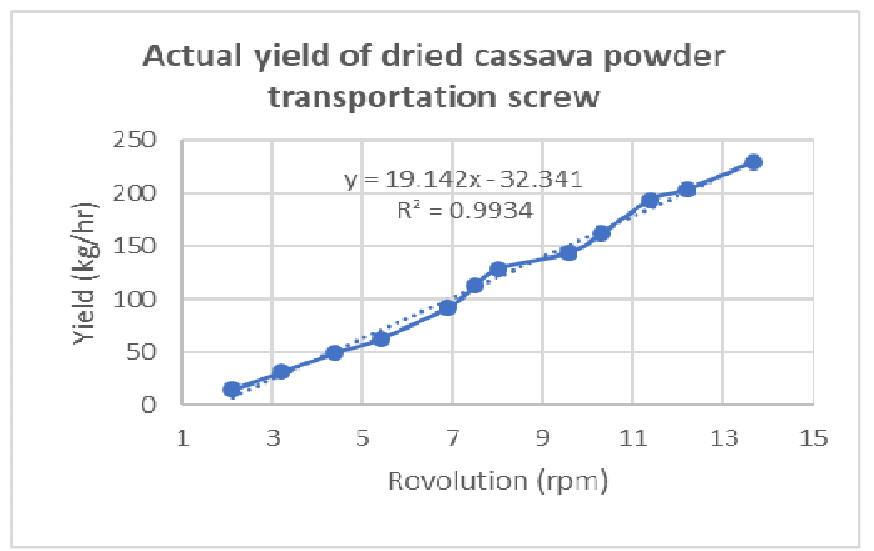

Fig. 6. The productivity of cassava starch loading screw according to the revolutions

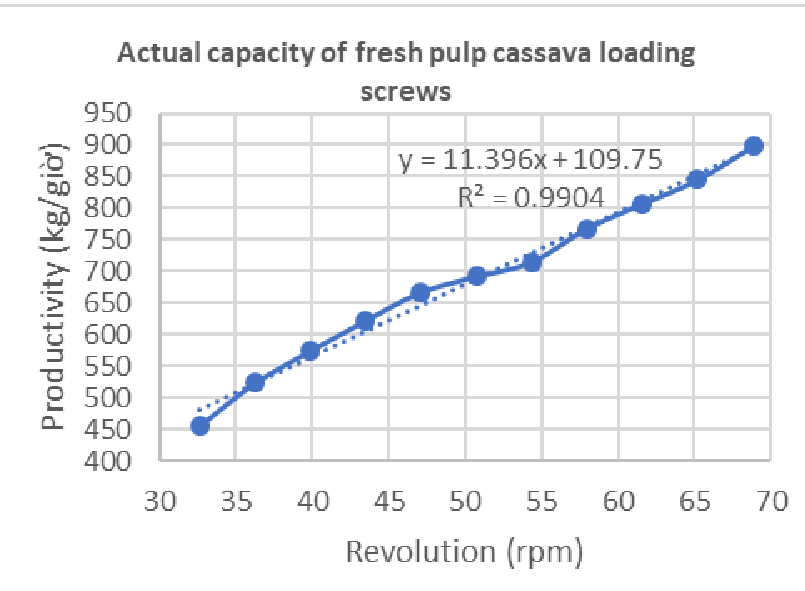

Fig.7. The capacity of fresh pulp cassava loading screw according to the revolutions

The test results show that the loading screw operation was stable with given parameters. The productivity of the fresh pulp cassava loading screw satisfies the mixer productivity. The actual capacity of the loading screw varies almost linearly with the screw revolution with a high correlation coefficient, R2 $=0.99$. This illustrates that the loading screw has been designed to match the loading material of fresh pulp. Actual screw yield for the experiments in this study was calculated according to empirical formula:

$$
Q=11.396 \times n+109.75[\mathrm{~kg} / \mathrm{hr}]
$$

According to experiment results, the experimental model is consistent with significance level $\alpha=0.01$.

\section{B. Experiment on mixing machine for dried cassava powder and cassava pulp}

The experimental purpose is to check the yield and uniformity of the system. In the experiments, the ratio of weight of dried cassava powder to fresh cassava pulp was given as 1:15, 1:10 and 1:5. Three times experimental trial was performed for each ratio. A capacity of the mixer about $750 \mathrm{~kg} / \mathrm{hr}$ was selected for the experiment. The productivity of the loading screw powder and pulp corresponding to the rotary speed of each screw is determined and shows in Table I.

TABLE I

\begin{tabular}{|c|c|c|c|}
\hline Weight ratio & 1:15 & 1:10 & $1: 5$ \\
\hline Dried cassava powder (kg/hr) & 46.875 & 68.182 & 125.000 \\
\hline Fresh cassava pulp (kg/hr) & 703.125 & 681.818 & 625.000 \\
\hline Mixing productivity (kg/hr) & 750.000 & 750.000 & 750.000 \\
\hline \multicolumn{4}{|c|}{ Rotary speed (rpm) } \\
\hline $\begin{array}{l}\text { Loading screw for dried cassava } \\
\text { powder }\end{array}$ & 4.140 & 5.250 & 8.220 \\
\hline $\begin{array}{l}\text { Loading screw for fresh cassava } \\
\text { pulp }\end{array}$ & 52.070 & 50.200 & 45.210 \\
\hline
\end{tabular}

SYSTEM SPECIFICATIONS FOR EXPERIMENTS 
The rotary speed of each feeding screw was adjusted for suitable with the requirement of experiments. The experiment was repeated three times corresponding to each specific rotary speed and yield. The volume of samples is directly weighed by electronic scales with a precision of 1 gram.

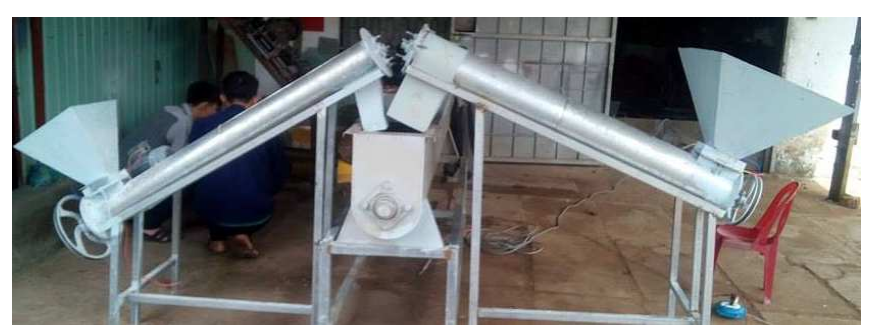

Fig. 8. Experiment device

1) Experiment result with the weight ratio of dried cassava powder to fresh cassava pulp 1:15

The experiment results shown in Table II indicates that the actual average productivity of the mixer is $752.85 \mathrm{~kg} / \mathrm{hr}$, it is light higher $0.38 \%$ in comparision with that of required productivity, but it is still acceptable for experiment. The actual ratio of dried cassava powder and fresh cassava pulp in this experiment was $1: 15.1$ which is equivalent to the selected ratio for experimentation of $1: 15$. The electricity consumption is about $2.84 \mathrm{kWh}$ for a ton of the mixing product.

2) Experiment result with the weight ratio of dried cassava powder to fresh cassava pulp 1:10

The experiment results shown in Table III indicates that the actual average productivity of the mixer is $753.68 \mathrm{~kg} / \mathrm{hr}$, it is light higher $0.49 \%$ in comparison with that of required productivity, but it is still acceptable for experiment. The actual ratio of dried cassava powder and fresh cassava pulp in this experiment was 1:9.99 which is equivalent to the selected ratio for experimentation of 1:10. The electricity consumption is about $2.83 \mathrm{kWh}$ for a ton of the mixing product.

3) Experiment result with the weight ratio of dried cassava powder to fresh cassava pulp 1:5

The experiment results shown in Table IV indicates that the actual average productivity of the mixer is $755.81 \mathrm{~kg} / \mathrm{hr}$, it is light higher $0.77 \%$ in comparison with that of required productivity, but it is still acceptable for experiment. The actual ratio of dried cassava powder and fresh cassava pulp in this experiment was 1:5.01 which is equivalent to the selected ratio for experimentation of 1:5. The electricity consumption is about $2.84 \mathrm{kWh}$ for a ton of the mixing product.

Through all 9 experiments on the designed mixer, it is said that:

- The design and fabrication of the mixer machine has satisfied the technical requirements. The feed rate can be exactly adjusted by adjustment of the screw rotation, and it shows a feasible agreement between theory calculation and experiment result.
- The capacity of each screw is controlled easily through changing the rotary speed of screw which is controlled by the inverter.

- The product after mixing is lighter, not lumps.

TABLE II

EXPERIMENT RESULT WITH THE WEIGHT RATIO OF DRIED CASSAVA POWDER TO FRESH CASSAVA PULP $1: 15$

\begin{tabular}{|c|c|c|c|c|c|c|}
\hline $\begin{array}{c}\text { Exp. } \\
\text { No. }\end{array}$ & $\begin{array}{c}\text { Mixing } \\
\text { time } \\
(\mathrm{s})\end{array}$ & $\begin{array}{c}\text { Dried } \\
\text { cassava } \\
\text { powder } \\
(\mathrm{g})\end{array}$ & $\begin{array}{c}\text { Fresh } \\
\text { cassava } \\
\text { pulp } \\
(\mathrm{kg})\end{array}$ & $\begin{array}{c}\text { Weight } \\
\text { total } \\
(\mathrm{kg})\end{array}$ & $\begin{array}{c}\text { Mixing } \\
\text { productivity } \\
\mathbf{Q}\end{array}$ & $\begin{array}{c}\text { Electricity } \\
\text { consumption } \\
(\mathrm{kWh})\end{array}$ \\
\hline 1 & 300 & 3925 & 59.5 & 63.43 & 761.1 & 0.18 \\
\hline 2 & 360 & 4789 & 69.6 & 74.39 & 743.9 & 0.213 \\
\hline 3 & 420 & 5515 & 82.4 & 87.92 & 753.6 & 0.249 \\
\hline
\end{tabular}

TABLE IIII

EXPERIMENT RESULT WITH THE WEIGHT RATIO OF DRIED CASSAVA POWDER TO FRESH CASSAVA PULP $1: 10$

\begin{tabular}{|c|c|c|c|c|c|c|}
\hline $\begin{array}{c}\text { Exp. } \\
\text { No. }\end{array}$ & $\begin{array}{c}\text { Mixing } \\
\text { time } \\
(\mathrm{s})\end{array}$ & $\begin{array}{c}\text { Dried } \\
\text { cassava } \\
\text { powder } \\
(\mathrm{g})\end{array}$ & $\begin{array}{c}\text { Fresh } \\
\text { cassava } \\
\text { pulp } \\
(\mathrm{kg})\end{array}$ & $\begin{array}{c}\text { Weight } \\
\text { total } \\
(\mathrm{kg})\end{array}$ & $\begin{array}{c}\text { Mixing } \\
\text { productivity } \\
\mathbf{Q}\end{array}$ & $\begin{array}{c}\text { Electricity } \\
\text { consumption } \\
(\mathrm{kWh})\end{array}$ \\
\hline 1 & 300 & 5710 & 55.60 & 61.310 & 735.72 & 0.174 \\
\hline 2 & 360 & 6852 & 69.45 & 76.302 & 763.02 & 0.22 \\
\hline 3 & 420 & 8056 & 80.88 & 88.936 & 762.31 & 0.25 \\
\hline
\end{tabular}

TABLE IIIV

EXPERIMENT RESULT WITH THE WEIGHT RATIO OF DRIED CASSAVA POWDER TO FRESH CASSAVA PULP 1:5

\begin{tabular}{|c|c|c|c|c|c|c|}
\hline $\begin{array}{c}\text { Exp. } \\
\text { No. }\end{array}$ & $\begin{array}{c}\text { Mixing } \\
\text { time } \\
(\mathrm{s})\end{array}$ & $\begin{array}{c}\text { Dried } \\
\text { cassava } \\
\text { powder } \\
(\mathrm{g})\end{array}$ & $\begin{array}{c}\text { Fresh } \\
\text { cassava } \\
\text { pulp } \\
(\mathrm{kg})\end{array}$ & $\begin{array}{c}\text { Weight } \\
\text { total } \\
(\mathrm{kg})\end{array}$ & $\begin{array}{c}\text { Mixing } \\
\text { productivity } \\
\mathbf{Q}\end{array}$ & $\begin{array}{c}\text { Electricity } \\
\text { consumption } \\
(\mathrm{kWh})\end{array}$ \\
\hline 1 & 300 & 10.5 & 53.00 & 63.500 & 762.00 & 0.180 \\
\hline 2 & 360 & 13.0 & 62.80 & 75.800 & 758.00 & 0.215 \\
\hline 3 & 420 & 14.2 & 73.00 & 87.200 & 747.43 & 0.248 \\
\hline
\end{tabular}

The post-mixing product of all experiments was evaluated by observation criteria and the use of a microscope. The pigments are mixed in the mixture to make the uniformity between the samples. This shows that all samples are uniformly mixed. It also shows the choice of continuous horizontal mixer is suitable for fresh pulp with high moisture content.
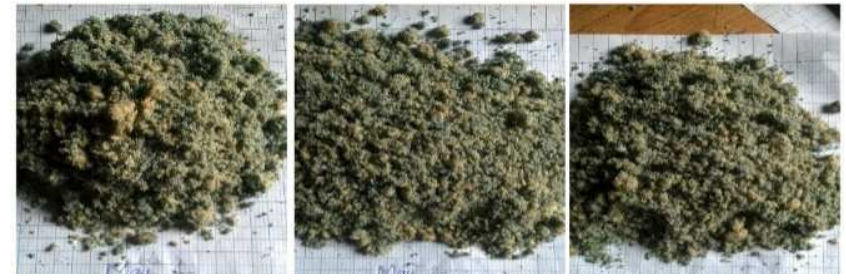

Fig.9. Samples of cassava pulp mixed with a weight ratio of 1:15 

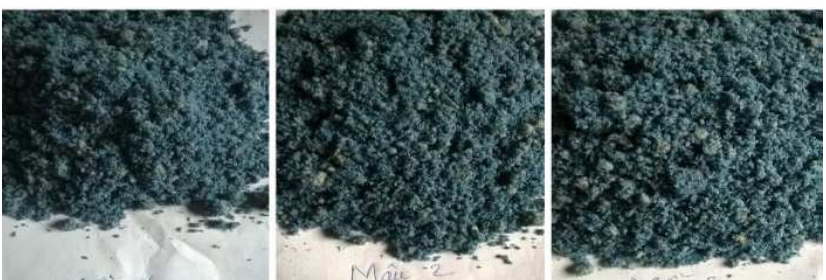

Fig.10. Samples of cassava pulp mixed with a weight ratio of 1:10
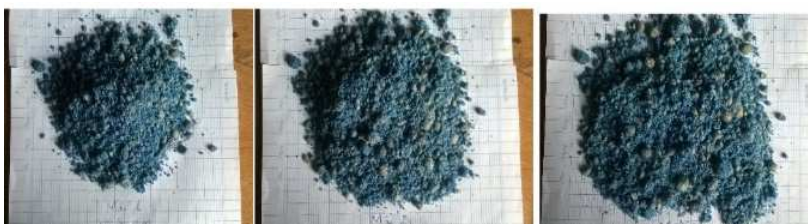

Fig.11. Samples of cassava pulp mixed with a weight ratio of 1:5

\section{Characteristics of cassava starch pellet after mixing}

The samples of cassava starch pellet mixed with dried powder and pressed on a flat plate-roller machine were experimented to evaluate the characteristics of the tablet. The parameters of the pressing machine are shown in Table 5. Experiment date are conducted and shown in Table 6.

TABLE V

SPECIFICATIONS OF PELLETIZING MACHINE

\begin{tabular}{|l|l|l|l|}
\hline No. & Parameters & Value & Unit \\
\hline 1 & Rotary speed & 150 & $\mathrm{rpm}$ \\
2 & Roller velocity & 155 & $\mathrm{rpm}$ \\
\hline 3 & $\begin{array}{l}\text { Gap between roller and mould } \\
\text { surface }\end{array}$ & 2 & $\mathrm{~mm}$ \\
\hline 4 & Supply capacity & 8 & $\mathrm{~kg} / \mathrm{min}$ \\
\hline 5 & Temperature of pressing chamber & 110 & ${ }^{\circ} \mathrm{C}$ \\
\hline 6 & Electricity comsumption & 2.3 & $\mathrm{kWh} / \mathrm{ton}$ \\
\hline
\end{tabular}

TABLE VI

MEASUREMENT RESULTS OF CASSAVA PULP PELLETS

\begin{tabular}{|l|l|l|l|}
\hline No. & Parameters & Value & Unit \\
\hline 1 & Average tablet length & 20.40 & $\mathrm{~mm}$ \\
\hline 2 & Average tablet diameter & 5.93 & $\mathrm{~mm}$ \\
3 & Tablet temperature outside & 95.5 & ${ }^{\circ} \mathrm{C}$ \\
4 & chamber & $\begin{array}{l}\text { Light } \\
\text { brown }\end{array}$ & \\
& Color & r. \\
\hline
\end{tabular}
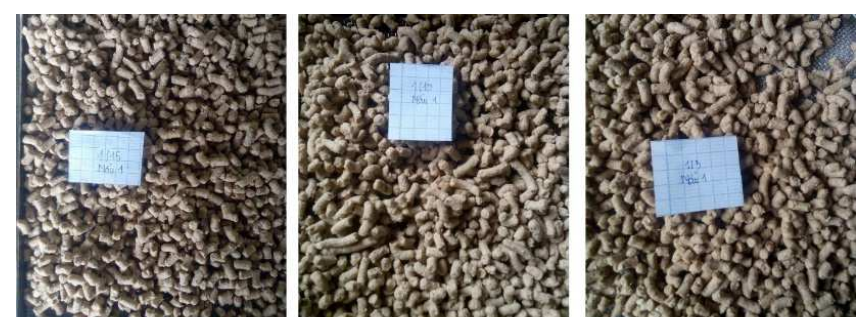

Fig.12. Cassava pulp after pelletizing and drying

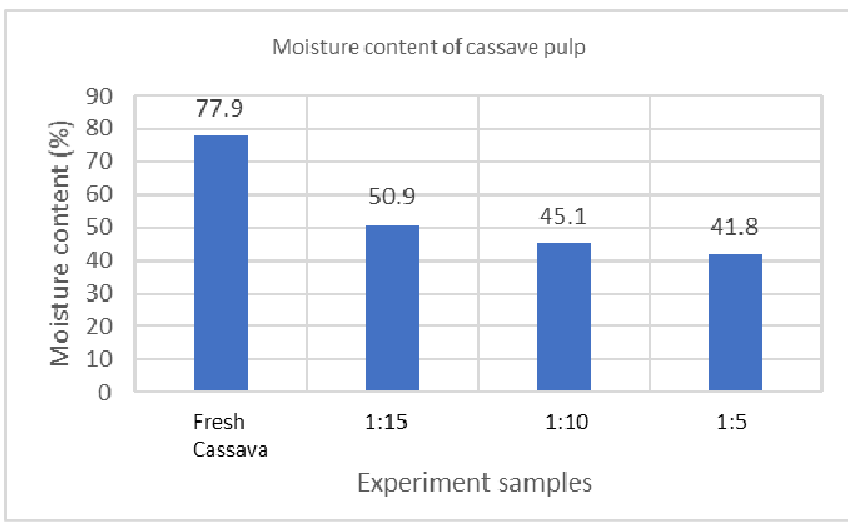

Fig.13. Moisture content of cassave pulp samples

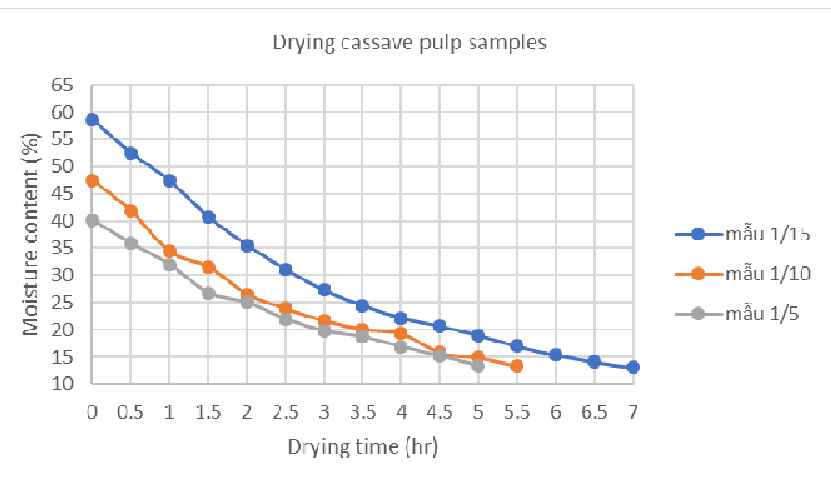

Fig.14. Moisture reduction curve for drying cassava pulp with different mixing ratios

\section{Experiment on drying cassava pulp pellet}

Moisture content of cassava residue pellets by different mixing ratios

Moisture content of cassava pulp samples was measured by oven method. And it is the mean value of three times measurement for each sample.

Moisture content of cassava pulp varies considerably from fresh cassava pulp due to two reasons: (1) mixing with dried cassava powder; (2) high pressing force during compressing the cassava pulp results in high material temperature. Thus, the tablet has reduced moisture very quickly after cooling. Besides, the moisture content of the pellet also depends on the mixture ratio with the dried cassava. Indeed, the moisture content of the material decreases as the ratio of cassava starch increases.

The drying temperature of cassava pulp was trial to find a feasible value. Thus, in these experiments, the suitable temperature is about $45 \pm 1^{\circ} \mathrm{C}$. The dryer uses hot air to reverse the drying agent that is suitable for drying cassava pulp with the following advantages such as uniformity cassava pulp drying, color retention as the original, simple operation, ability to change machine structure with high productivity. The cassava tablet has a high moisture removal rate that results in a short drying time to achieve a moisture content of $13 \%$.

The samples with a higher dried powder percentage will need a shorter drying time to reach the drying requirement. Indeed, the experiment results shows that the drying time for the samples with a mixing ratio of 1:15 was significantly different from those of the other two samples. It is because 
of the small cassava ratio in the mixing powder. Besides, the gelatinization rate in the process of pressing is not large, so the speed of moisture removal after pressing is higher than the other two samples. The electricity consumption for two samples with the mixing ratio of $1: 5$ and $1: 10$ is about 10.2 $\mathrm{kWh} /$ ton, and $15 \mathrm{kWh} /$ ton for the ratio of $1: 15$.

\section{E. Evaluation of technical parameters of cassava residue tablet by mixing ratios}

\section{1) Moisture content of cassava residue pellets by different mixing ratios}

The breaking force of cassava pulp increases significantly as the mixing ratio of cassava starch increases. The compressive strength of the pellets with the mixing ratios of $1: 10$ and 1:5 is much higher in comparison with that of cassava pulp without mixing dried powder. Besides, the cassava pulp with mixing ratio of $1: 15$ is statistically significant in comparison with the samples with mixing ratios of $1: 10$ and 1:5. The breaking force of pellet with $1: 10$ and $1: 5$ ratio is greater than $2 \mathrm{kG}$, that satisfies the quality requirements according to the Vietnam Standard TCVN 102: 2004.

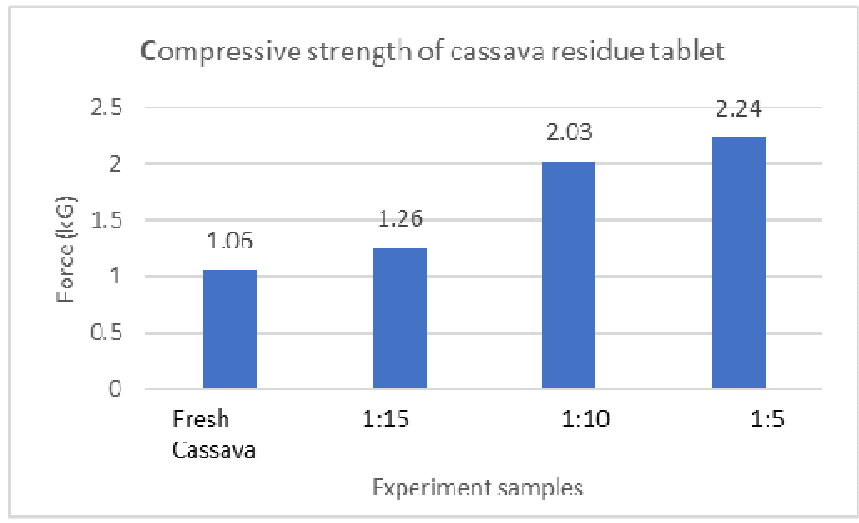

Fig.15. Compressive strength of cassava residue tablet by mixing ratios
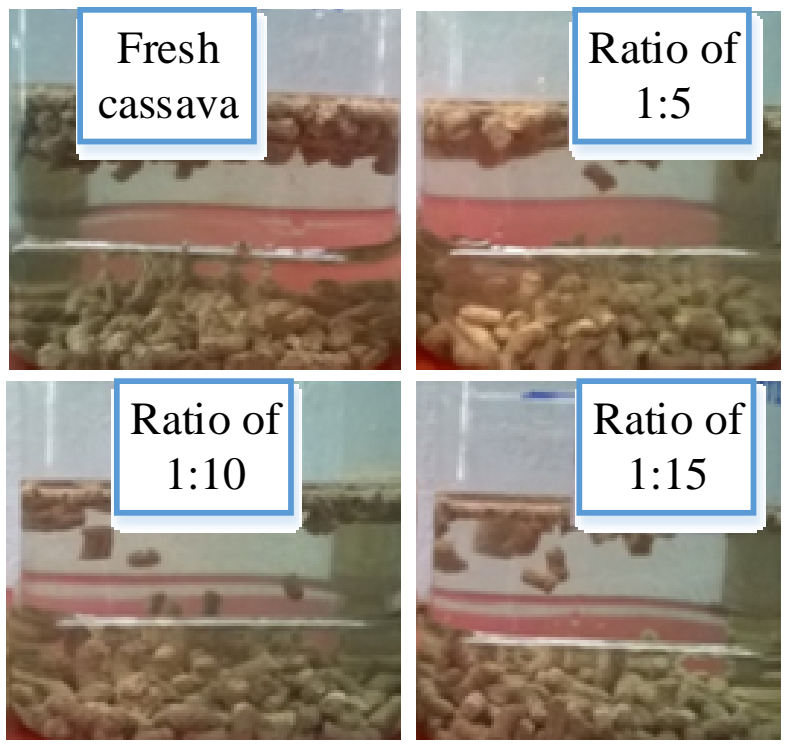

Fig.16. Determination of water endurance and duration of cassava pulp

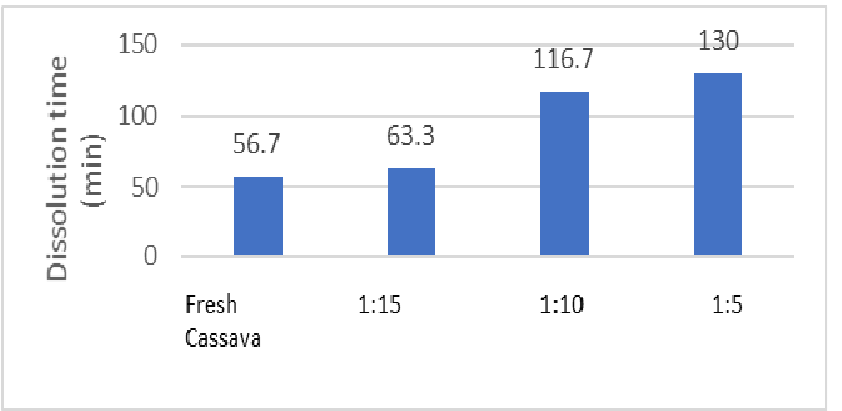

Fig.17. Water dissolution time of cassava pulp by mixing ratios

\section{2) Results of water disintegration time of cassava pulp samples}

The time to start dissolving of cassava pulp samples increased from 56.7 minutes (for fresh cassava sample without mixing dried powder) to 130 minutes (for mixing ratio 1:5). That indicates the strength of the cassava residue pellets increased as the starch content in cassava pulp increased. The cassava residue pellet with the mixing ratio of 1:15 is smaller and significantly different from the other two samples. The experiment results of water endurance and duration of tablet shows that cassava pulp corresponding to the mixing ratio of 1:5 and 1:10 has achieved the required compressibility, meeting the requirements of quality tablets, and they can be stored for long term.

Looking at the entire production line from mixing, pressing, drying, it can be said that cassava pulp with a 1:15 mixing ratio does not meet the required compressive strength, as well as durable time when immersed in water. This rate is not suitable to produce pellets from cassava pulp. The other mixing ratios, which are 1:10 and 1:5, result is good quality pellets that satisfy all required technical specifications, but the power cost for all stages is not significantly different. Therefore, in terms of economic aspect, the mixing ratio between dried flour and fresh cassava of 1:10 is suitable for the pellet production line in this study.

The specific volume of the dried pelleted capsules has increased to about $700 \mathrm{~kg} / \mathrm{m} 3$, therefore, it has met the given requirements, such as volume reduction to facilitate transportation, longer storage time because of low moisture content after drying (about 13\%), preventing it producing Aflatoxin toxins during storage. Besides, the environmental pollution for both water and air from the cassava processing establishments can be avoided. Especially, it makes use of agricultural waste, improves economic efficiency of the agricultural products.

\section{CONCLUSIONS}

A production line used to produce pelleted pellets from the utilization of fresh cassava pulp bringing from cassava starch processing plants was proposed and successfully tested. The models in the line were properly tested with available measuring instruments at Faculty of Engineering and Technology, University of Agriculture and Forestry, Ho Chi Minh City. Thus, the reliable experiment results were also shown.

The recommended equipment for scale-up in an industrial production scale includes a continuously horizontal screw 
feeder; a flat plate - vertical rollers pressing machine; flatbed dryer with ability of reversing the drying agent.

The production of pellets from cassava pulp will bring more economic and technical efficiency, especially to solve the problem of environmental pollution. In addition, in an industrial production scale, this is also a solution to create new investment direction, diversification of livestock products, and contribution to the overall development of Vietnamese society.

It is necessary to develop the production line of pelletizing feeder equipment with a large capacity according to the capacity of cassava starch processing factories to have technology experiment in an industrial production scale. Therefore, the technology applications used in production will be more practical and reliable.

\section{ACKNOWLEDGMENT}

This research is funded by the Hanoi University of Science and Technology (HUST) under project number T2016-LN-09.

\section{REFERENCES}

[1] FAO. Why Cassava? retrieved on Oct 2017. Available: http://www.fao.org/ag/AGP/agpc/gcds/index_en.html

[2] Anna Burns, Roslyn Gleadow, Julie Cliff, Anabela Zacariasand Timothy Cavagnaro, Cassava: The Drought, War and Famine Crop in a Changing World, Sustainability, 2, 3572-3607, 2010.

[3] FAO, 2016, Cassava, production quantity (tons) - for all countries, retrieved on Oct 2017. Available: http://www.factfish.com/statistic/cassava\%2C\%20production\%20qua ntity
[4] FAO, The global cassava strategy for cassava: transforming a traditional tropical root crop, retrieved on Oct 2017. Available: http://www.fao.org/docrep/006/y0169e/y0169e04.htm

[5] Annual report of Mard for 2016, retrieved on Oct 2017 from www.omard.gov.vn/upload/files/Cục\%20Trồng\%20trọt.doc.

[6] MARD's report, retrieved on Oct 2017. Available: https://khcn.mard.gov.vn

[7] Sriroth K, Chollakup R, Chotineeranat S, Piyachomkwan K and Oates C G, Processing of cassava waste for improved biomass utilization. Bioresource Technolology, 2000, 71(1):63-69.

[8] K. Sriroth. R. Chollakup, Processing of cassava waste for improved biomass utilization, Bioresource Technol, 2000, vol. 71, pp. 63-69.

[9] Apichai S., Sirima S.J, Sunthorn K., Kaemwich J., Efficient utilization of cassava pulp for succinate production by metabolically engineered Escherichia coli KJ122, Bioprocess Biosyst Eng (2015) 38:175-187.

[10] A. O. Ubalua, Cassava wastes: treatment options and value addition alternatives, African Journal of Biotechnology, 19 September 2007, Vol. 6 (18), pp. 2065-2073.

[11] Weekly Report Cassava and Starch Market, Vietnam Cassava Association. Available: http://hiephoisanvietnam.org.vn/.

[12] Tu V.P, Nguyen T.T, Chu K.S., Luong H.N., Nguyen T.H.D, Bennett B., Naziri D., Tomlins K., To K.A, Potential use of by-products for animal feed from cassava in viet nam, J. Sci. \& Devel. 2016, Vol. 14, No. 1: 93-100.

[13] Hung D.V., The Design, Constrution and Testing of a Cassava Pulp Dewatering Machine, 2012, Master thesis, Nong Lam University HCMC, Vietnam.

[14] Nguyen D.L, Calculation and design a cassava pulp pellet machine with capacity of $500 \mathrm{~kg} / \mathrm{hr}, 2014$, Bachelor thesis, Nong Lam University HCMC, Vietnam.

[15] Nguyen D.T, Ngo T.Q, Design and construction a wet cassava pulp mixing machine for animal feed industry, 2017, Bachelor thesis, Nong Lam University HCMC, Vietnam. 